\title{
Ağır metal iyonlarının tarımsal atıklar ile biyosorpsiyonunun araştırılması
}

\author{
Investigation of biosorption of heavy metal ions by the agricultural wastes
}

\author{
Elif Hatice Gürkan ${ }^{1, *}$ \\ ${ }^{1}$ Ondokuz Mayls Üniversitesi, Kimya Mühendisliği Bölümü, 55100, Samsun, Türkiye
}

\begin{abstract}
Özet
$\mathrm{Su}$, yaşamın sürdürülebilirliği için gerekli bir kaynaktır. Endüstriyel, tarımsal ve insan aktiviteleri, su kaynaklarının kirliliğine katkı sağlamaktadır. Ağır metaller, su kaynaklarındaki en önemli kirleticilerden biridir. Düşük konsantrasyonlarda bile ciddi hastalıklara sebep olur. Su kaynaklarından ağır metallerin giderilmesi için kimyasal, fiziksel ve biyolojik arıtma yöntemleri kullanılır. Düşük maliyetli tarımsal ürünler, ağır metal gideriminde çevredostu ve ekonomik çözüm sağlar. Bu çalışmanın amaçları, (1) biyokütlenin karakterizasyonu, (2) $\mathrm{Cu}(\mathrm{II})$ ve $\mathrm{Zn}(\mathrm{II})$ iyonlarının biyokütle üzerine adsorpsiyonun değerlendirilmesi, (3) biyokütlenin biyosorpsiyon analizidir.
\end{abstract}

Anahtar kelimeler: Biyokütle, Biyosorpsiyon, Tarımsal atık, Bakır, Çinko

\section{Giriş}

Bilimsel ve teknolojik gelişmeler, yaşam koşullarını iyileştirmeye katkı sağlarken uzun vadede yaşamı ve ekolojiyi tehdit eden sorunları beraberinde getirmektedir [1]. Sanayileşme, insan ve çevre üzerine etkileri açısından değerlendirildiğinde, bilimsel ve teknolojik gelişmelerin en önemlisidir. Artan sanayileşme faaliyetleri ile makineleşme ve üretim artarken, yaşam standartları ve kentleşmede de artış görülmektedir. Bunun sonucunda şehir merkezlerinde, sanayi tesislerinde ve tarımsal faaliyetler sonucunda önemli miktarlarda sağlığa zararlı biyolojik ve kimyasal maddeleri içeren atık sular oluşmaktadır [2-3].

Atık sular; yer altı suları, akarsu, göl ve denizlerde oluşan çevre kirliliğinin en önemli kaynağıdır. Atık sularda çevre kirliliğine neden olan; radyoaktif atıklar, ağır metal bileşikleri, siyanür, organik ve çözücüler, aromatik ve alifatik hidrokarbonlar bulunmaktadır.

Sağlık Ölçüm ve Değerlendirme Enstitüsü (Institute for Health Metrics and Evaluation, IHME) verileri; ağır metallerin toksisiteleri ve biyolojik sistemlerde birikme eğilimlerinin, onların sağlık için yüksek risk faktörü olduğunu göstermiştir. Ağır metal kirliliği, havada (yanma, ayırma ve işleme), yüzey sularında (depolama ve taşınma sırasında sızıntı) ve toprakta (yer altı suları ve tarım) olmaktadır. Çevreye dağılan ağır metallerin insan vücudundaki etkisi, konsantrasyon, temas süresi, temas

\begin{abstract}
Water is an essential source for the sustainable of life. Industrial, agricultural and human activities contribute to pollution of water sources. Heavy metals are one of the most important contaminants in the water sources. They are toxic elements even at low concentration which can cause severe diseases. Chemical, physical and biological treatment methods are used to remove the heavy metals from the water sources with a different degree of success. Low-cost by-products from agricultural have been recognized as an eco friendly and economically solution for the removal of heavy metals. The objectives of this study were (1) characterization of the biomass, (2) assessment of the biosorption experiments of the biomass to compare $\mathrm{Cu}$ (II) and $\mathrm{Zn}$ (II), and (3)analysis of the biosorption ability of the biomass.
\end{abstract}

Keywords: Agricultural waste, Biomass, Biosorption, Copper, Zinc

sıklığı, çevresel ve bireysel etmenlere göre değişiklik gösterir.

Ağır metaller limit değerleri aştığında, insan fizyolojisi ve diğer biyolojik sistemler üzerinde zararlı bir etkiye sahip olduğu bilinmektedir. Ağır metaller organizmaya solunum, sindirim ve deri teması ile alınır ve vücuttan kolaylıkla atılamazlar. Dışarıdan alınan bu maddeler, canlı organizmalarda biyolojik olarak parçalanamadığı için kolaylikla besin zincirine girebilmekte ve canlı organizmalarda birikmektedir [4-5]. Biriktiği organa, etkilediği sisteme bağlı olarak psikolojik rahatsızlıklardan fizyolojik sorunlara kadar geniş bir yelpazede hastalık oluşturabilir.

Metalik kirlenmelerin çoğu sularda toplanır. Çünkü; çevre kirliliğinden en çok, en çabuk ve en kolay etkilenen sudur. Endüstriyel faaliyetlerden kaynaklanan atıksulardaki metal içeriği, çevreye verilmeden önce arıtılarak su kirliliği kontrolü yönetmeliğine göre izin verilen değerlerin altına düşürülmesi gerekmektedir [6].

Ağır metal içeren endüstriyel atıksular iyon değiştirme, koagülasyon, filtrasyon, ters osmoz, nötralizasyon ve kimyasal çöktürme, biyosorpsiyon, buharlaştırma, membran filtrasyon ve elektrokimyasal yöntemleriyle arıtılmaktadır. Biyosorpsiyon, kirleticilerin biyolojik olarak aktif olmayan, ucuz, doğal ve ölü biyokütleler ile giderimi prosesidir [7].

$\mathrm{Bu}$ çalışmada, fistık kabuğu ve pirinç kabuğu ile atıksulardan $\mathrm{Cu}(\mathrm{II})$ ve $\mathrm{Zn}(\mathrm{II})$ gideriminde $\mathrm{pH}$, temas süresi

\footnotetext{
* Sorumlu yazar/ Corresponding author, e-posta / e-mail: elif.gurkan@ omu.edu.tr (E. H. Gürkan)

Geliș / Recieved: 17.08.2021 Kabul / Accepted: 22.03.2021 Yayımlanma / Published: 27.07.2021

doi: 10.28948/ngmuh.780933
} 
ve başlangıç metal konsantrasyonu gibi değişkenlerin etkisi incelenmiştir. Deneysel verilerin, çeşitli kinetik ve izoterm modelleri kullanılarak kinetik ve denge analizleri gerçekleştirilmiştir.

\subsection{Ağır Metaller}

Ağır metal yoğunluğu $5 \mathrm{~g} / \mathrm{cm}^{3}$ 'den daha büyük olan metaller olarak tanımlanmaktadır $[8,9]$. Bu gruba bakır $(\mathrm{Cu})$, civa $(\mathrm{Hg})$, çinko $(\mathrm{Zn})$, demir $(\mathrm{Fe})$, gümüş $(\mathrm{Ag})$, kadmiyum $(\mathrm{Cd})$, krom (Sn), kobalt (Co), kurşun $(\mathrm{Pb})$, mangan $(\mathrm{Mn})$, ve nikel (Ni) olmak üzere 60' dan fazla metal dahil edilebilir. Bakır, çinko, nikel, demir, bor, molibden gibi metaller düşük konsantrasyonlarda ve limit değerlerini aşmadığı sürece canlıların büyümesine katkı sağlamaktadır.

Ağır metallerin ekolojik sistemde salınımının, doğal çevrimlerden çok insanın neden olduğu etkiler nedeniyle olduğu görülmektedir. Doğal çevrimler ve kullanıma bağlı kirlenmenin yanı sıra kazaların da ağır metallerin çevreye salınımında önemli bir etkiye sahip olduğu bilinmektedir. Araştırmalara göre, doğal çevrimler sonucu; 7600 ton/y1l kadmiyum, 18800 ton/y1l arsenik, 3600 ton/y1l cıva, 332000 ton/yıl kurşun atmosfere salınmakta iken insan faaliyetleri sonucu; selenyumun (19 kat), kadmiyumun (8 kat), civa, kurşun, kalayın (6 kat), arsenik, nikel ve kromun (3 kat) daha fazla miktarda deşarj edildiği görülmüştür [9]. Ağır metallerin çevreye salınımında etken olan en önemli endüstriyel faaliyetler; madencilik, ilaç, elektrokaplama, kauçuk ve plastik, organik kimyasallar, pestisitler ve demir çelik gelmektedir [9-13]. Farklı endüstriyel faaliyetlerden açığa çıkan metaller Tablo 1'de verilmiştir.

Tablo 1. Temel endüstrilerden açığa çıkan metaller [14].

\begin{tabular}{|c|c|c|c|c|c|c|c|c|}
\hline Endüstri Kolu & $\mathrm{Cd}$ & $\mathrm{Cr}$ & $\mathrm{Cu}$ & $\mathrm{Hg}$ & $\mathrm{Pb}$ & $\mathrm{Ni}$ & $\mathrm{Sn}$ & $\mathrm{Zn}$ \\
\hline Kağıt & - & + & + & + & + & + & - & - \\
\hline Petrokimya & + & + & - & + & + & - & + & + \\
\hline Klor-alkali üretimi & + & + & - & + & + & - & + & + \\
\hline Gübre & + & + & + & + & + & + & - & + \\
\hline Demir-çelik & + & + & + & + & + & + & + & + \\
\hline Enerji üretimi (Termik) & + & + & + & + & + & + & + & + \\
\hline
\end{tabular}

\subsubsection{Ağır metallerin etkileri}

Ağır metaller, biyolojik reaksiyonlara katılma derecelerine göre yaşamsal ve yaşamsal olmayan olarak siniflandirılırlar. Organizma yapısında belirli bir konsantrasyonda bulunması gerekli olan vitamin ve hormonların bileşenlerinde bulunan ve biyolojik reaksiyonlara katıldıkları için düzenli olarak besin yoluyla alınmaları zorunlu olanlar yaşamsal olarak sinıflandırılır. Ancak, limit konsantrasyonların (1-10 ppm) üzerinde toksik etki gösterirler $(\mathrm{Cu}, \mathrm{Fe}, \mathrm{Ni}$ Se ve $\mathrm{Zn})$. Yaşamsal olmayan ağır metaller $(\mathrm{Cd}, \mathrm{Hg}$ ve $\mathrm{Pb})$ ise, çok düşük konsantrasyonlarında bile toksik etki göstermektedir. Bir ağır metalin yaşamsal olup olmadığı organizmaya bağlı olarak değişmektedir (nikel, bitkiler için toksik etki gösterirken, hayvanlarda iz elementi olarak bulunması gerekir) $[4,11]$.
Ağır metaller, antropolojik yani volkanik faaliyetler ve endüstriyel faaliyetler sonucu atmosfere, pedosfere ve hidrosfere yayılmaktadır. Organizmaya solunum, sindirim ve deri yolu ile giren biyolojik olarak parçalanamayan ağır metaller, metabolizmadan çok yavaş atılabildiği için, birikerek tehlikeli konsantrasyonlara ulaşmakta ve toksikolojik etki yaratmaktadır. Ağır metallerin vücutta meydana getirdiği hastalıklar, otoimmün hastalıklar (kardiyovasküler hastalıklar, ülseratif kolit, tümör, romatizma vb.) organik hastalıklar (alerji, astım, böbrek hastalığı, egzama, kısırlık vb) ve nörolojik bozuklukları (alzheimer, parkinson, depresyon, migren) olarak sıralanabilir $[8,15]$. Aynı zamanda, tarımsal ve sucul alanları koruma, kötü koku ve görünümü engelleme, içme ve kullanma suyu kaynaklarındaki kirliliği önleme, sucul yaşamı korumak ve su kanallarındaki kirliliği önlemek için atıksulardan ağır metal giderimi yapılmalıdır [16].

\subsubsection{A ğır metallerin giderim yöntemleri}

Atıksulardan ağır metal kirliliğini gidermek için fiziksel, kimyasal ve biyolojik esaslı yöntemler geliştirilmiştir (Şekil 1). Ağır metal giderimi için; kimyasal koagülasyon ve flokülasyon, elektrokimyasal yöntemler, membran filtrasyonu, iyon değişimi, biyoremediasyon ve biyosorpsiyon en çok kullanılan yöntemlerdir [17, 18].

Koagülasyon, ağır metal içeren atıksuların arıtımında veya ön arıtımında düşük maliyetleri nedeniyle yaygın olarak uygulanmaktadır. Bununla birlikte çamur üretimine sebep olmaktadır. Fizikokimyasal ve biyolojik prosesler, fazla çamur oluşumu, yüksek işletme maliyetleri, atıksu türüne bağlı olarak değişkenlik gösterir.

Elektrokoagülasyon, kolloidlerin, süspansiyonların ve emülsiyonların elektriksel yüklerden etkilenmesi prensibine dayanır [20]. Bazı avantajları nedeniyle elektrokoagülasyon prosesi, endüstriyel atıksuların arıtılmasında etkili bir yöntem olarak kullanılmaktadır. Elektrokimyasal prosesler, uzun süreli kullanımlarda az problemli ve daha az masraflı olabilir. Ağır metal içeren atıksuların arıtımında, hızlı ve iyi kontrol edilebilir bir yöntemdir. $\mathrm{Bu}$ avantajlar elektrokoagülasyon yönteminin yaygın olarak kullanılmasını sağlamaktadır, Ancak çamur oluşumuna neden olmazken, yüksek elektrik maliyeti prosesin uygulanabilirliğini kısıtlamaktadır [17, 21]. Membran filtrasyon, atıksulardan ağır metal gideriminde etkili bir yöntemdir [22]. Bu yöntemin en büyük avantaj1, düşük işletme maliyeti ile yüksek giderim verimi sağlamasıdır. Prosesin dezavantajı, giderim sonrası açığa çıkan kirlenmiş membranlar ve yüksek enerji maliyetleridir [23]. İyon değişim prosesinde, çözelti içerisinde giderilmesi amaçlanan iyonlar elektrostatik kuvvetler yardımıyla reçine üzerindeki iyonlar ile yer değiştirir. İyon değiştirme yönteminde, yatırım ve işletme maliyetleri yüksektir. $\mathrm{Bu}$ yöntem, yüksek konsantrasyonlarda kirlilik içeren endüstriyel atıksuların arıtımı için uygulandığında, iyon değiştirici reçineleri kısa sürede doygunluğa ulaşır ve rejenere edilmesi veya değiştirilmesi gerekir. Reçinelerin rejenerasyonunda kullanılan kimyasallar, ikincil kirletici olarak çevreye zarar vermektedir [24, 25]. 


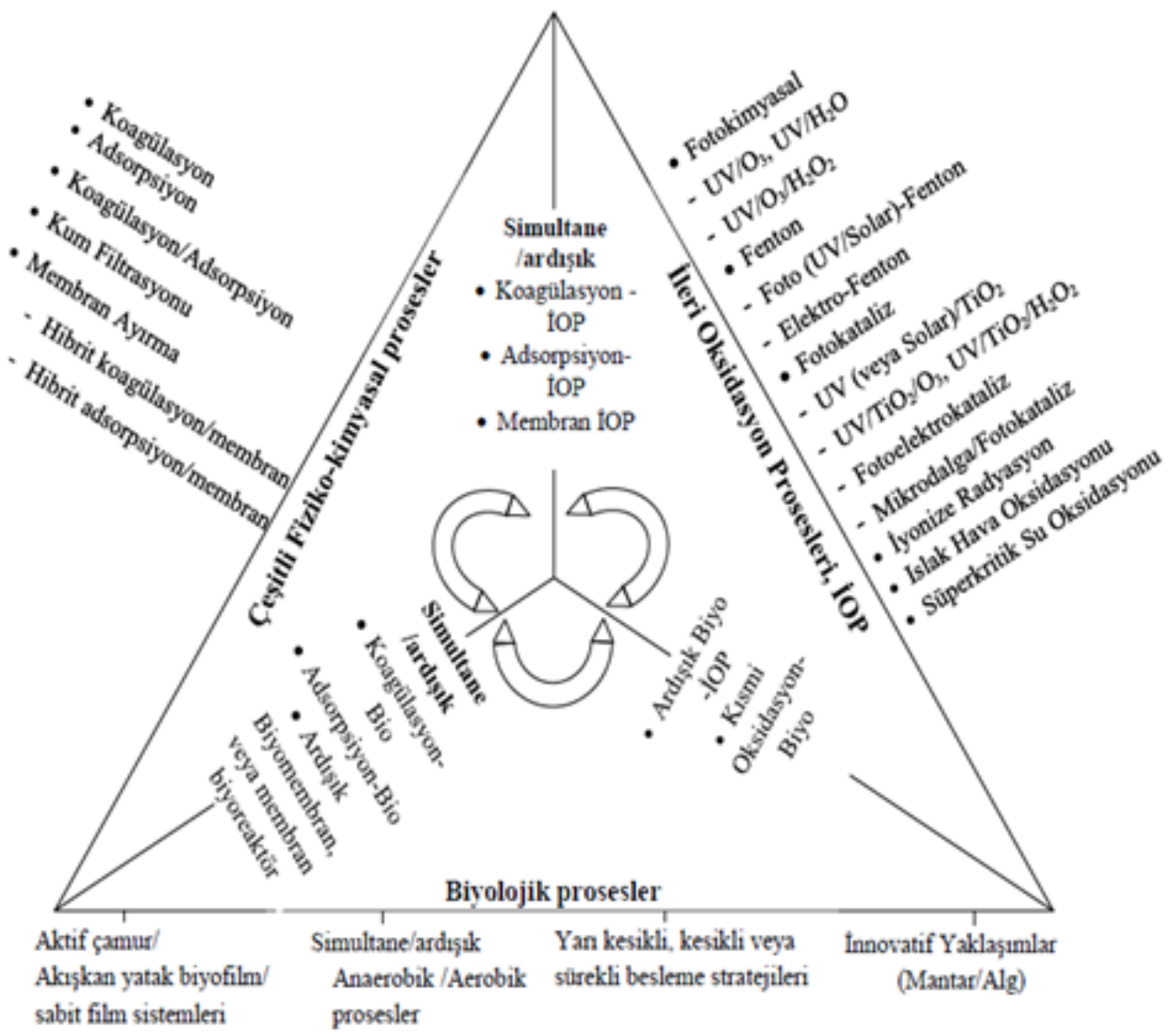

Şekil 1. Atıksuların arıtımında kullanılan prosesler [19].

Adsorpsiyon en ekonomik, etkili ve verimli bir prosestir. Proses, maddenin bir fazdan ayrılarak diğer bir fazda birikmesi esasına bağlı olarak, ara yüzeylerde gerçekleşmektedir. Atıksuların arıtımında sıvı-katı adsorpsiyonu kullanılır. Katı-sıvı adsorpsiyonu, çözelti içindeki çözünmüş (adsorbat) maddelerin adsorbent yüzeyinde tutularak çözeltiden uzaklaştırılması esasına dayanır. Atıksudan adsorbent üzerine iyon akışı, çözeltide kalan iyonların, adsorplanmış madde konsantrasyonu ile denge haline gelinceye kadar devam eder. Dengeye ulaşıldığında iyon transferi durur ve kararlı hal şartları meydana gelir [26, 27].

\subsubsection{Sorbentler}

Adsorpsiyona etki eden faktörlerin başlıcaları yüzey alanı,adsorbentin yapısı ve tanecik boyutu, karıştırma hızı, adsorbatın çözünürlüğü ve molekül büyüklüğü, ortamın pH değeri, temas süresi ve sıcaklıktır. Adsorpsiyon işlemi için etkin ve verimli adsorbent seçimi oldukça önemlidir.

Aktif karbon, farklı hammaddelerden üretildiği için yüzey alanı, fonksiyonel gruplar, yüzey yükleri, büyüklük ve porozite gibi farklı yüzey özelliklerine sahiptir [28].Farklı yüzey özellikleri, atıksulardan ağır metal gideriminde etkin kullanım alanı sağlar [29-31].

Ancak; yüksek maliyet ve sinırlı rejenerasyon davranışları, aktif karbon uygulamalarını kısıtlamaktadır. Tarımsal faaliyetler sonucunda açığa çıkan atıklar (şeker kamışı küspesi [32], greyfurt kabuğu [33], patates kabuğu
[34], çay atığı [35], Hindistan cevizi kabuğu [36], çekirdek kabuğu [37], pirina [38], atıksulardan ağır metal gideriminde alternatif adsorbent olarak kullanılmaktadır (Tablo 2).

Tarımsal atıkların yapısında, potansiyel adsorpsiyon kapasitesini etkileyen hemiselüloz, lignin, yağlar, proteinler, şeker, su, hidrokarbonlar ve nişasta bulunmaktadır $[39,40]$. Tarımsal atıklar, doğal ve modifiye formda kullanılır. Doğal formda; materyal yıkanır, kurutulur ve istenilen partikül büyüklüğüne kadar eleme işlemine tabi tutulur ve adsopsiyon prosesinde kullanılırken modifiye formda, materyal modifikasyon teknikleri ile ön işleme tabi tutulur ve adsopsiyon prosesinde kullanılabilir. $\mathrm{Bu}$ ön işlemlerin amacı, aktif alanları genişletmek için fonksiyonel grup potansiyelini artırmaktır [40]. Endüstriyel faaliyetler sonucu açı̆̆a çıkan endüstriyel atıklar da adsorbent olarak kullanılmaktadır. Endüstriyel atıklar; (i) uçucu kül, (ii) demir-çelik endüstrisi atıkları (yüksek firın cürufu, atık çamuru, toz)(iii) alüminyum endüstrisi atıkları (kırmızı çamur), (iv) gübre endüstrisi atıkları ve (v) diğer endüstriyel atıklar olarak ayrılır.

Son yıllarda yapılan çalışmalarda, arıtma çamurunun atıksulardaki fenollerin, ağır metallerin ve boyaların gideriminde kullanıldığ görülmektedir [41, 42]. Kitosan, turba yosun, deniz yosunu ve algler adsorbent olarak kullanılmaktadır. Adsorbent olarak yaygın olarak kullanılan diğer bir grup; kil, zeolit, sediment ve topraktır. 
Tablo 2. Farklı biyokütlelerin ağır metal gideriminde sorbent olarak kullanımı

\begin{tabular}{|c|c|c|c|}
\hline Adsorbent & Ağır metal & Biyosorpsiyon kapasitesi $\left(\mathrm{mg} \mathrm{g}^{-1}\right)$ & Referans \\
\hline Agave küspesi & $\mathrm{Zn}(\mathrm{II})$ & $7.84 \mathrm{mg} \mathrm{g}^{-1}$ & [32] \\
\hline Fındık kabuğu & $\mathrm{Cu}(\mathrm{II})$ & $8.00 \mathrm{mg} \mathrm{g}^{-1}$ & [43] \\
\hline Arpa küspesi & $\mathrm{Cu}(\mathrm{II})$ & $4.64 \mathrm{mg} \mathrm{g}^{-1}$ & [44] \\
\hline Pomelo kabuğu & $\mathrm{Cu}(\mathrm{II})$ & $21.10 \mathrm{mg} \mathrm{g}^{-1}$ & [45] \\
\hline Hindistan cevizi ağaci talaşı & $\mathrm{Cu}(\mathrm{II})$ & $3.89 \mathrm{mg} \mathrm{g}^{-1}$ & [46] \\
\hline Hindistan cevizi ağacı talaşı & $\mathrm{Zn}(\mathrm{II})$ & $23.81 \mathrm{mg} \mathrm{g}^{-1}$ & [46] \\
\hline Patates kabuğu & $\mathrm{Cu}(\mathrm{II})$ & $0.38 \mathrm{mg} \mathrm{g}^{-1}$ & [34] \\
\hline Nar kabuğu & $\mathrm{Cu}(\mathrm{II})$ & $1.32 \mathrm{mg} \mathrm{g}^{-1}$ & [47] \\
\hline Mercimek kabuğu & $\mathrm{Cu}(\mathrm{II})$ & $15.62 \mathrm{mg} \mathrm{g}^{-1}$ & [48] \\
\hline Buğday kabuğu & $\mathrm{Cu}(\mathrm{II})$ & $11.00 \mathrm{mg} \mathrm{g}^{-1}$ & [48] \\
\hline Limon kabuğu & $\mathrm{Cu}(\mathrm{II})$ & $1111.10 \mathrm{mg} \mathrm{g}^{-1}$ & [49] \\
\hline Yerfistığ kabuğu & $\mathrm{Cu}(\mathrm{II})$ & $13.1579 \mathrm{mg} \mathrm{g}^{-1}$ & Bu çalışmada \\
\hline Yerfistı̆̆ kabuğu & $\mathrm{Zn}(\mathrm{II})$ & $6.9444 \mathrm{mg} \mathrm{g}^{-1}$ & Bu çalışmada \\
\hline Pirinç kabuğu & $\mathrm{Cu}(\mathrm{II})$ & $12.9870 \mathrm{mg} \mathrm{g}^{-1}$ & Bu çalışmada \\
\hline Pirinç kabuğu & $\mathrm{Zn}(\mathrm{II})$ & $11.6279 \mathrm{mg} \mathrm{g}^{-1}$ & Bu çalışmada \\
\hline
\end{tabular}

\section{Materyal ve metot}

\subsection{Materyal}

Çalışmada kullanılan pirinç kabuğu (PK) Samsun, Terme'de bulunan pirinç fabrikasından, yer fistığı kabuğu (YK) Samsun, Tekkeköy'de bulunan kuruyemiş fabrikasından temin edilmiştir. Biyosorpsiyon öncesi, yer fistığ 1 ve pirinç kabuğu saf su ile yıkanarak, $50^{\circ} \mathrm{C}$ 'de etüvde 48 saat kurutulmuş, ögütülmüş ve elenerek biyosorpsiyon işlemleri için kullanılabilir hale getirilmiştir.

Kullanılan kimyasallar, standart yöntem ve metotlara uygun hazırlanmıştır. Çinko ve bakır stok çözeltileri (1000 ppm); $\mathrm{C}_{4} \mathrm{H}_{6} \mathrm{O}_{4} \mathrm{Zn} .2 \mathrm{H}_{2} \mathrm{O}$ ve $\mathrm{Cu}\left(\mathrm{NO}_{3}\right)_{2} .6 \mathrm{H}_{2} \mathrm{O}, 1000 \mathrm{~mL}$ deiyonize su içerisinde çözülerek elde edilmiştir.

\subsection{Materyallerin karakterizasyonu}

Numunelerin biyosorpsiyon öncesi ve sonrası yüzey element analizleri, taramalı elektron mikroskobu (SEM) ve enerji dağılımlı spektrometresi (EDS) ile yapılmıștır. Ayrıca, numunelerin moleküler bileşimini ve yapısını belirlemek için Fourier transform kızılötesi spektroskopisi (FTIR) kullanılmıştır.

\subsection{Biyosorpsiyon çalışmaları}

Biyosorpsiyon çalışmaları, adsorban miktarı, $\mathrm{pH}$ ve ağır metallerin başlangıç konsantrasyonu parametrelerindeki değişime göre yürütülmüştür.

Biyosorpsiyon çalışmaları, $25^{\circ} \mathrm{C}$ sıcaklıkta, $50 \mathrm{~mL}$ çalışma, hacminde, $250 \mathrm{~mL}$ 'lik erlenlerde, $150 \mathrm{rpm}$ karıştırma hızına sahip çalkalamalı su banyosunda gerçekleştirilmiştir. Biyosorpsiyon çalışmaları süresince, sicaklık $\left(20-70^{\circ} \mathrm{C}\right)$, sorbent miktarı $(5-20 \mathrm{~g} / \mathrm{L}), \mathrm{pH}(3-11)$, temas süresi ve başlangıç konsantrasyonu (25-200 mg L) etkisi incelenmiştir. Çözeltilerin $\mathrm{pH}^{\prime} 1 \mathrm{HCl}$ ve $\mathrm{NaOH}$ kullanılarak ayarlanmıştır. Çözeltide kalan $\mathrm{Cu}$ (II) ve $\mathrm{Zn}$ (II) konsantrasyonu atomik adsorpsiyon spektrofotometresi (Unicam 929) ile analiz edilmiştir.

\section{Bulgular ve tartışma}

\subsection{Materyallerin karakterizasyonu}

Şekil 2'de YK'na ait SEM görüntüsünde gözenekli yapıya sahip olduğu gözlemlenmiştir. Bu gözenekli yapı, biyosorpsiyon prosesine olumlu yansimakta ve $\mathrm{Cu}$ (II) ve Zn(II) iyonlarının adsorplanmasını arttırmaktadır YK'nun bakır biyosorpsiyonu sonrası SEM görüntüleri (Şekil 3) ve çinko biyosorpsiyonu sonrası SEM görüntüleri (Şekil 4) incelendiğinde ise adsorplanan ağır metallerin YK yüzeyine etkileri gözlemlenmektedir.

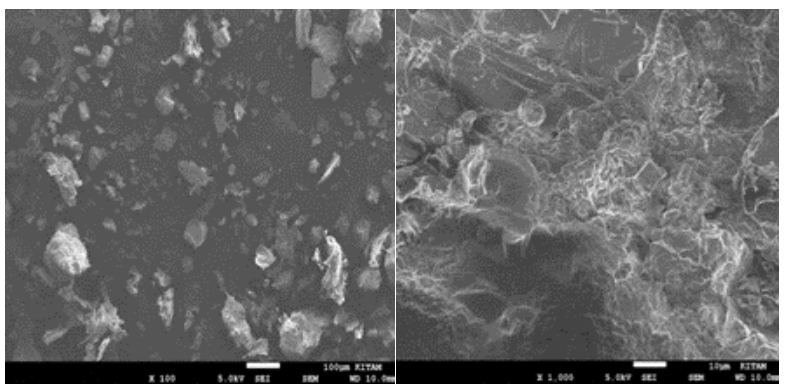

Şekil 2. YK'nun biyosorpsiyon öncesi SEM görüntüleri, (a) $\mathrm{x} 100$, (b) $\times 1000$

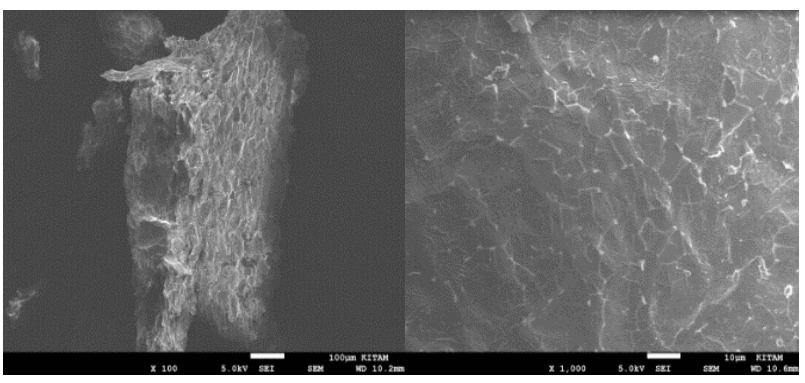

Şekil 3. YK'nun bakır biyosorpsiyon sonrası SEM görüntüleri, (a)x100,(b) x1000 


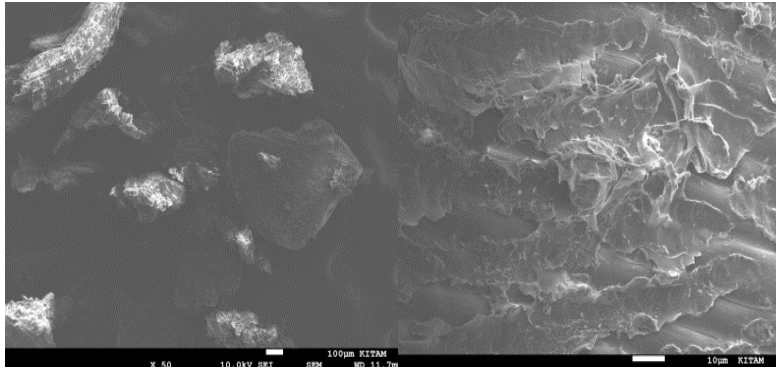

Şekil 4. YK'nun çinko biyosorpsiyon sonrası SEM görüntüleri, (a)x100,(b) x1000

YK'nun biyosorpsiyon öncesi, bakır ve çinko biyosorpsiyonu sonrası EDS görüntüleri Şekil 5(a,b,c)'de yer almaktadır. YK'nun biyosorpsiyon öncesi EDS spektrumu (Şekil 6a); oksijen, potasyum, alüminyum, magnezyum, demir, sülfür, sodyum vb. gibi yapıların varlığını göstermektedir. YK'nun bakır biyosorpsiyonu sonrasında çekilen EDS spektrumu; bakır biyosorpsiyonunun başarılı bir şekilde gerçekleştiğini gösteren bakır pikini (Şekil 6b), çinko biyosorpsiyonu sonrasında çekilen EDS spektrumu; çinko biyosorpsiyonunun başarılı bir şekilde gerçekleştiğini gösteren çinko pikini (Şekil 6c) göstermektedir. Biyosorpsiyon sonrası spektrumlarda, biyosorpsiyon öncesi spektrumunda çıkan diğer elementler işaretlenmediği için gösterilmemiştir.

PK'nun SEM görüntüleri (Şekil 7), yüzeyin sıralı şekilde tepeciklere sahip olan bir yapıda olduğunu göstermektedir. PK'nun bakır biyosorpsiyonu sonrası SEM görüntüleri (Şekil 8) ve çinko biyosorpsiyonu sonrası SEM görüntüleri (Şekil 9) incelendiğinde; adsorplanan metal iyonlarının PK yüzeyine etkileri görülmektedir.

PK'nun biyosorpsiyon öncesi, bakır ve çinko biyosorpsiyonu sonrası EDS görüntüleri Şekil 10(a,b,c)'de yer almaktadır. PK'nun bakır biyosorpsiyonu sonrasında çekilen EDS spektrumunda bakır biyosorpsiyonunun başarılı bir şekilde gerçekleştiğini gösteren bakır piki (Şekil 11.b), çinko biyosorpsiyonu sonrasında çekilen EDS spektrumunda çinko biyosorpsiyonunun başarılı bir şekilde gerçekleştiğini gösteren çinko piki (Şekil 11.c) gözlemlenmiştir.

YK ve PK'nun FTIR spektrumları Şekil 12'de gösterilmiştir. Şekil 12'de verilen pirinç kabuğuna ait FTIR spektrumunda, $1000 \mathrm{~cm}-1$ 'de ( $\mathrm{Si}-\mathrm{O}-\mathrm{Si})$ da C-OH bağı ve $\mathrm{Si}-\mathrm{O}$ bağının titreşimlerinin üst üste gelmesinden kaynaklandığı kabul edilmiştir. Bu noktadaki yüksek pik, C$\mathrm{OH}$ grubunun $1200-1000 \mathrm{~cm}-1$ aralığındaki gerilme piklerinin ve $\mathrm{Si}-\mathrm{O}$ bağının gerilme piklerinin üst üste binmesinden kaynaklanmaktadır [50]. Yer fistığı kabuğu için FTIR spektrumları incelendiğinde, $1024 \mathrm{~cm}-1$ 'de karakteristik pik C-O esnemesine titreşimini göstermektedir[51].
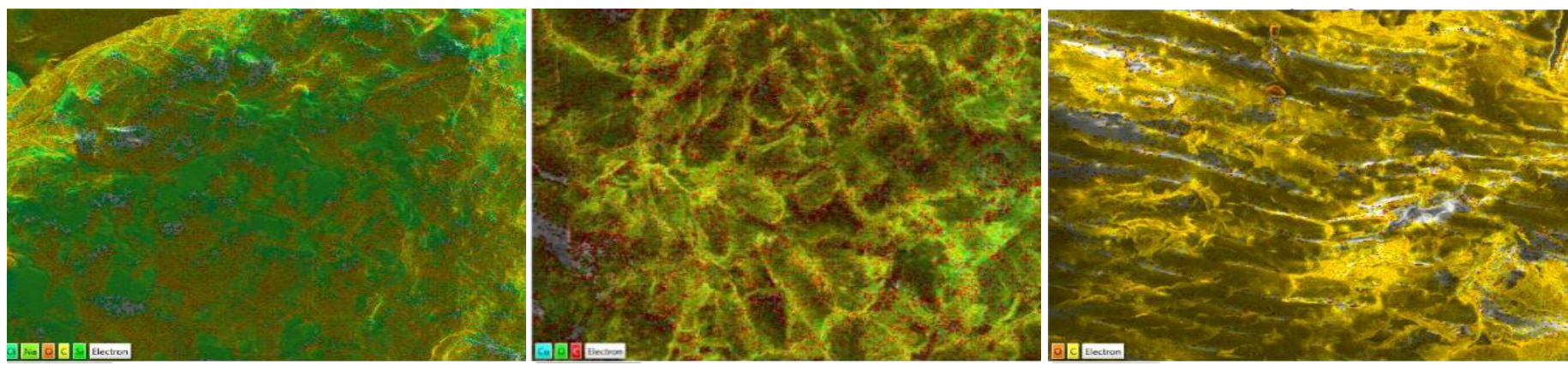

Şekil 5. (a) YK'nun biyosorpsiyon öncesi EDS görüntüsü, (b) YK'nun bakır biyosorpsiyonu sonrası EDS görüntüsü (T:25 ${ }^{\circ} \mathrm{C}$,

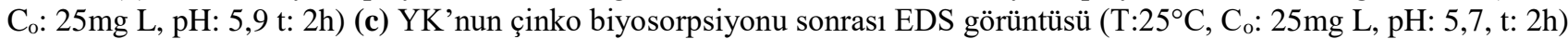
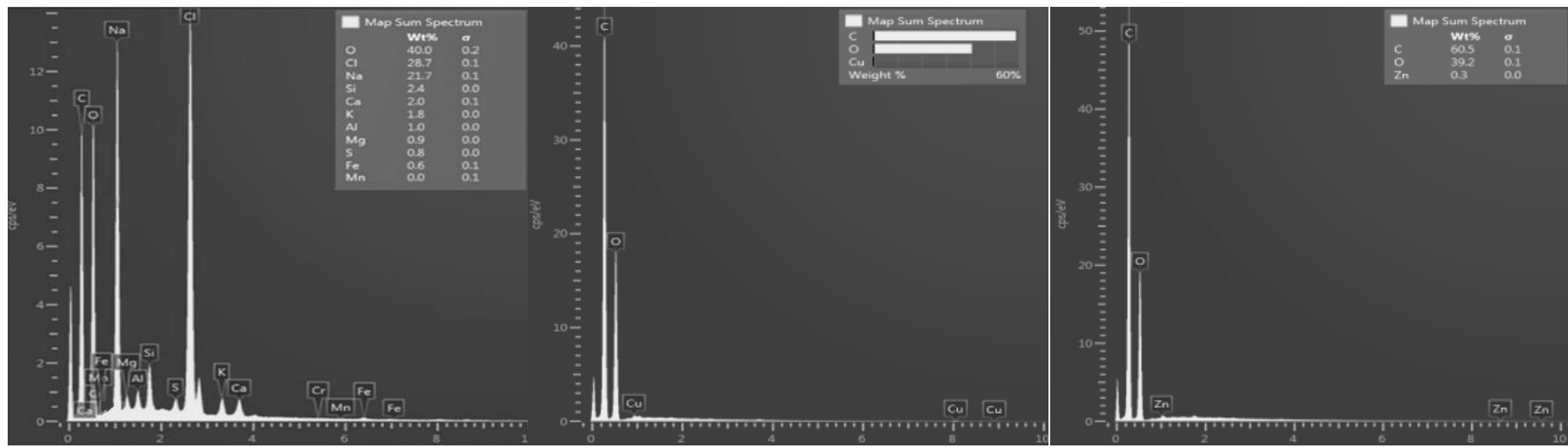

Şekil 6. (a) YK'nun biyosorpsiyon öncesi EDS spekturumu, (b) YK'nun bakır biyosorpsiyonu sonrası EDS spekturumu, (c) YK'nun çinko biyosorpsiyonu sonrası EDS spekturumu 


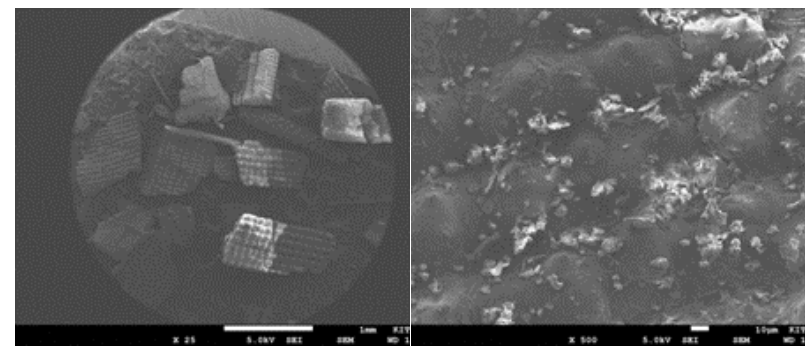

Şekil 7. PK'nun biyosorpsiyon öncesi SEM görüntüleri, (a)X100, (b)x 1000

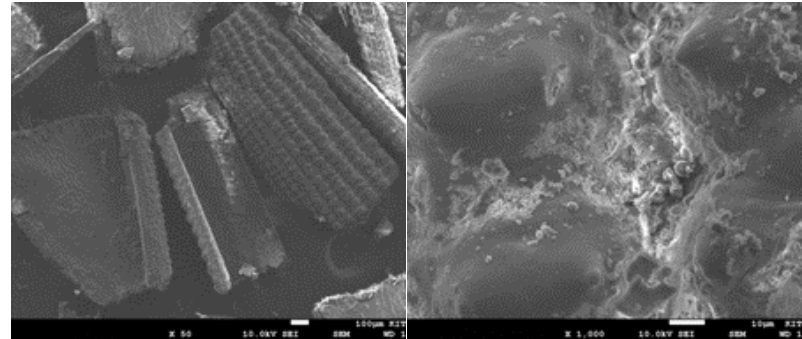

Şekil 8. PK'nun bakır biyosorpsiyon sonrası SEM görüntüleri, (a)x100,(b)x1000

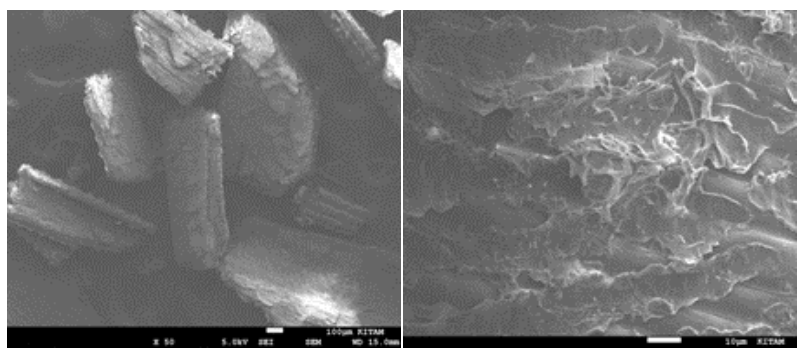

Şekil 9. PK'nun çinko biyosorpsiyon sonrası SEM görüntüleri, (a)x100,(b)x1000
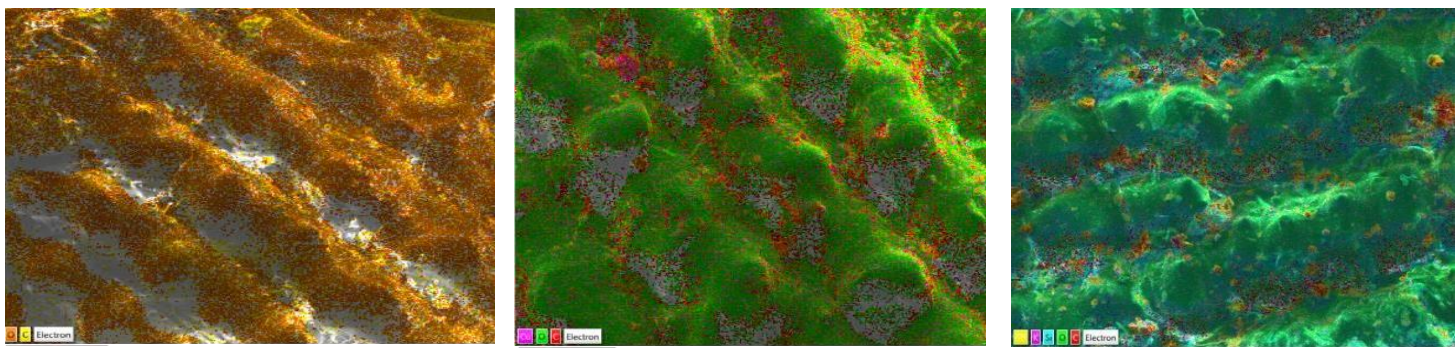

Şekil 10. (a) PK'nun biyosorpsiyon öncesi EDS görüntüsü, (b) PK'nun bakır biyosorpsiyonu sonrası EDS görüntüsü $\left(\mathrm{T}: 25^{\circ} \mathrm{C}, \mathrm{C}_{\mathrm{o}}: 25 \mathrm{mg} \mathrm{L}^{-1}, \mathrm{pH}: 5,9, \mathrm{t}: 2 \mathrm{~h}\right)$ (c) $\mathrm{PK}$ 'nun çinko biyosorpsiyonu sonrası EDS görüntüsü $\left(\mathrm{T}: 25^{\circ} \mathrm{C}, \mathrm{C}_{\mathrm{o}}: 25 \mathrm{mg} \mathrm{L}^{-1}, \mathrm{pH}: 5,7, \mathrm{t}: 2 \mathrm{~h}\right)$
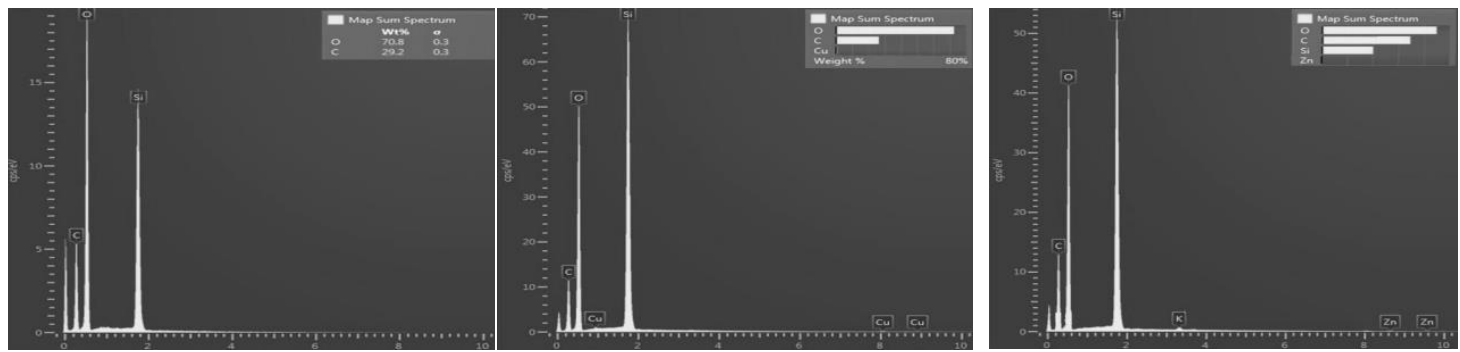

Şekil 11 (a) PK'nun biyosorpsiyon öncesi EDS spekturumu, (b) PK'nun bakır biyosorpsiyonu sonrası EDS spekturumu (c) PK'nun çinko biyosorpsiyonu sonrası EDS spekturumu

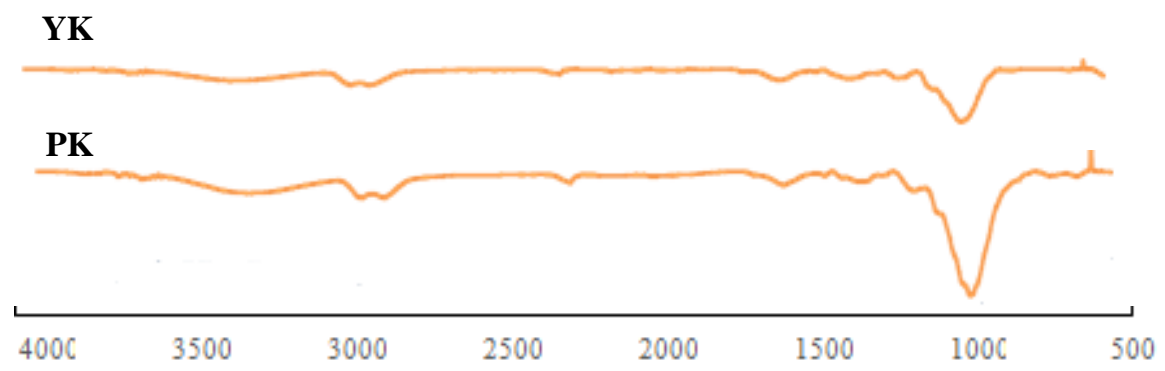

Şekil 12.YK ve PK'nun FTIR spektrumları 


\section{2 pH Değişiminin biyosorpsiyon üzerine etkisi}

Biyosorpsiyon çalışmaları, $\mathrm{pH} ; 3-11$ aralığında, $25^{\circ} \mathrm{C}$ sıcaklıkta, $25 \mathrm{mg} \mathrm{L}^{-1}$ başlangıç metal konsantrasyonunda, $180 \mathrm{dk}$ sürede gerçekleştirilmiştir. Şekil 13'de, pH artarken, $\mathrm{Cu}(\mathrm{II})$ ve $\mathrm{Zn}(\mathrm{II})$ sorpsiyon kapasitesinin $\operatorname{arttığ}$ görülmektedir. Düşük pH'larda, ortamda daha fazla $\mathrm{H}^{+}$ iyonlarının bulunması; sorbent üzerindeki aktif bölgelere metal iyonlarının bağlanmasını engellemektedir. $\mathrm{pH}$ değeri arttıkça, fonksiyonel grupların deprotonize olması (proton bırakma) ile sorbent yüzeyinin negatif yükü artar. Sorbent üzerindeki negatif yüklü aktif bölgelere, pozitif yüklü metal iyonlarının bağlanması ile biyosorpsiyon kapasitesinde artış görülmektedir $[52,53]$.
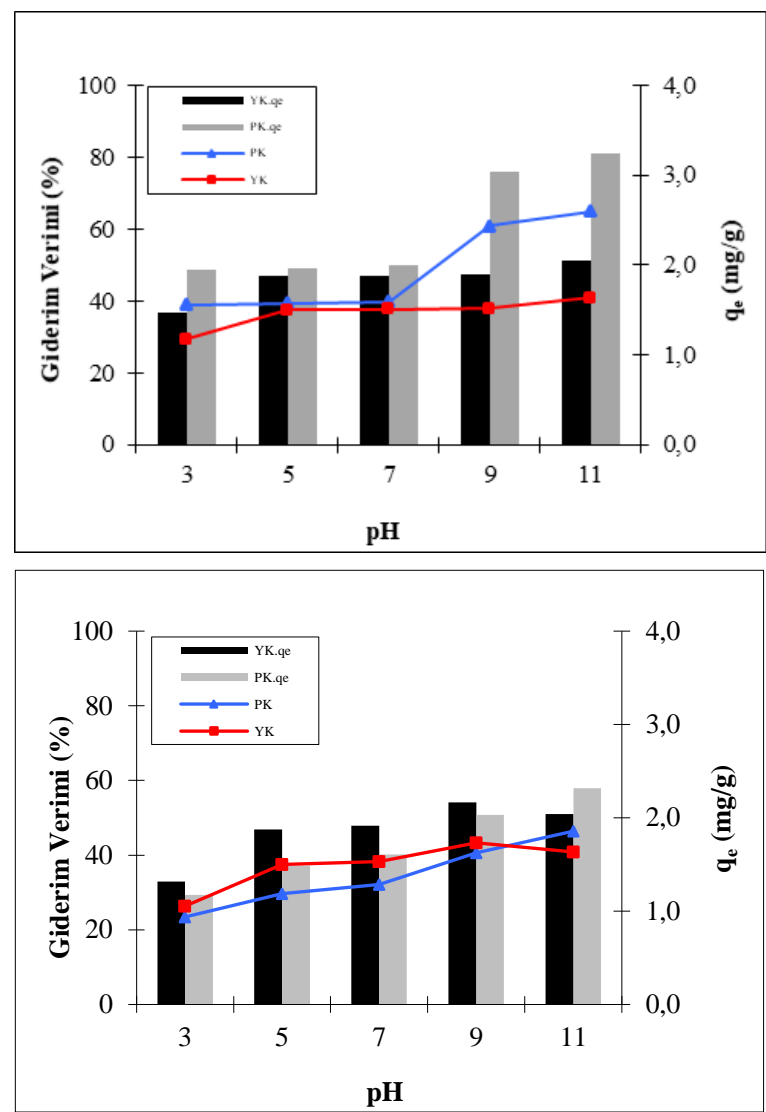

Şekil 13. (a) YK ve PK ile bakır biyosorpsiyonu üzerine pH etkisi, (b) YK ve PK ile çinko biyosorpsiyonu üzerine $\mathrm{pH}$ etkisi

\subsection{Biyosorpsiyon izotermleri}

Biyosorpsiyon izotermleri, adsorpsiyon sistemlerinin dizaynı ve analizi için kullanılan temel araçlardandır. İzotermler, sabit sicaklıktaki bir adsorpsiyon prosesinin dengeye ulaştığ 1 anda adsorbentin birim kütle başına adsorplayabileceği madde miktarı ve akışkan fazdaki madde konsantrasyonu arasındaki ilişkiyi verir. Biyosorpsiyon çalışmalarında elde edilen veriler, Langmuir, Freundlich ve Temkin izotermlerine göre değerlendirilmiş ve eşitliklerin düzenlenmiş halleri Tablo 3'de ifade edilmiştir [53].

Langmuir izoterm model, homojen bir yüzeyde tek tabakalı adsorpsiyonun varlığını gösterir. Yüzeyin her noktasında, adsorpsiyon enerjisinin aynı olduğunu ve yüzeyde tutunan adsorbat molekülleri arasında etkileşimin olmadığı varsayımına dayanmaktadır. Freundlich izoterm model, heterojen bir yüzeyde çok tabakalı adsorpsiyonun varlığını gösterir. Temkin izoterm model, yüzeyde adsorplanan adsorbat molekülleri arasındaki etkileşimi açıklamaktadır [54].

Adsorpsiyon izoterm modelleri korelasyon katsayılarına $\left(\mathrm{R}^{2}\right)$ göre karşılaştırıldığında, her bir izoterm modelin deneysel çalışma verileri ile uyumlu olduğu görülmüştür (Tablo 4). Deneysel verilerin, Langmuir, Freundlich ve Temkin izoterm modellerine uygunluk göstermesi, biyosorpsiyon çalışmalarının hem heterojen hem de homojen yüzeylerde gerçekleşebildiğini ve adsorbat molekülleri arasında etkileşim olabildiğini göstermektedir.

\subsection{Biyosorpsiyon kinetikleri}

Biyosorpsiyon kinetik çalıșmaları ile, sorpsiyon işleminin tamamlanması için gerekli temas süresini belirleyen sorpsiyon hizı belirlenebilmektedir

$\mathrm{FK}$ ve $\mathrm{PK}$ üzerine $\mathrm{Cu}(\mathrm{II})$ ve $\mathrm{Zn}(\mathrm{II})$ iyonlarının biyosorpsiyon kinetiği, yalancı birinci dereceden, yalancı ikinci dereceden, Elovich ve Bangham modellerine göre incelenmiş ve eşitliklerin düzenlemiş halleri Tablo 5 'de ifade edilmiştir.

$\mathrm{Cu}(\mathrm{II})$ ve $\mathrm{Zn}(\mathrm{II})$ iyonlarının FK ve PK ile giderilmesinde, biyokütle yüzeyindeki ağır metal konsantrasyon değişimini esas alan yalancı birinci derece, yalanc1 ikinci derece, Elovich ve Bangham kinetik modellerine ait regresyon katsayıları $\left(\mathrm{R}^{2}\right)$ incelendiğinde, en yüksek değerlerin yalancı ikinci derece kinetik modelinden elde edildiği görülmektedir (Tablo 6). Bu sonuçlara göre, ağır metallerin biyokütle ile sorpsiyonu için en uygun kinetik model; yalancı ikinci derece kinetik modeldir.

Tablo 3. $\mathrm{Cu}$ (II) ve $\mathrm{Zn}$ (II) iyonlarının biyosorpsiyonunun izoterm modelleri

\begin{tabular}{llll}
\hline Izoterm Model & İzoterm Eşitlikleri & Parametreler \\
\hline \multirow{2}{*}{ Langmuir } & $\frac{C_{e}}{q_{e}}=\frac{1}{q_{m} K_{L}}+\frac{C_{e}}{q_{m}}$ & $q_{e}$ & dengedeki metal iyonu konsantrasyonu $\left(\mathrm{mg} \mathrm{g}^{-1}\right)$, \\
& $q_{m}$ & maksimum biyosorpsiyon kapasitesi $\left(\mathrm{mg} \mathrm{g}^{-1}\right)$, \\
& $K_{L}$ & Langmuir biyosorpsiyon sabiti $\left(\mathrm{L} \mathrm{mg}^{-1}\right)$, \\
Freundlich & $n$ & boyutsuz bir parametre, \\
& $\log q_{e}=\log K_{f}+\left(\frac{1}{n}\right) \log C_{e}$ & $K_{F}$ & Freundlich izoterm sabiti $\left(\mathrm{L} \mathrm{mg}^{-1}\right)$, \\
& $B$ & adsorpsiyon enerjisinin değişmesidir $\left(\mathrm{J} \mathrm{mol}^{-1}\right)$, \\
Temkin & $q_{e}=B \cdot \ln K_{T}+B \cdot \ln C_{e}$ & & Tempkin izotermi bağlanma sabiti $\left(\mathrm{L} \mathrm{mg}^{-1}\right)$, \\
\hline
\end{tabular}


Tablo 4. $\mathrm{Cu}(\mathrm{II})$ ve $\mathrm{Zn}$ (II) iyonlarının biyosorpsiyonunun izoterm parametreleri

\begin{tabular}{|c|c|c|c|c|c|}
\hline \multicolumn{2}{|c|}{ İzoterm modelleri } & \multicolumn{2}{|c|}{$\mathrm{Cu}$ (II) } & \multicolumn{2}{|c|}{ Zn (II) } \\
\hline & & YK & PK & YK & PK \\
\hline \multirow{3}{*}{ Langmuir } & $q_{m}\left(m g g^{-1}\right)$ & 13.1579 & 12.9870 & 6.9444 & 11.6279 \\
\hline & $K_{L}\left(L m^{-1}\right)$ & 0.0115 & 0.0136 & 0.0147 & 0.0091 \\
\hline & $R^{2}$ & 0.9420 & 0.9450 & 0.9100 & 0.9450 \\
\hline \multirow{3}{*}{ Freundlich } & $n$ & 0.6119 & 0.7027 & 0.5952 & 0.7220 \\
\hline & $K_{f}\left(L \boldsymbol{m g}^{-1}\right)$ & 4.3954 & 5.2844 & 9.3325 & 9.3541 \\
\hline & $R^{2}$ & 0.9760 & 0.9210 & 0.9250 & 0.9390 \\
\hline \multirow{3}{*}{ Temkin } & $b$ & 909.1912 & 830.0080 & 1570.7617 & 1034.7815 \\
\hline & $\boldsymbol{K}_{T}\left(\boldsymbol{L} \boldsymbol{m g}^{-1}\right)$ & 0.1275 & 0.1294 & 0.1393 & 0.1031 \\
\hline & $R^{2}$ & 0.9553 & 0.9601 & 0.9896 & 0.9944 \\
\hline
\end{tabular}

Tablo 5. Cu(II) ve $\mathrm{Zn}$ (II) iyonlarının biyosorpsiyonunun kinetik modelleri

\begin{tabular}{|c|c|c|}
\hline Kinetik Model & Kinetik Eşirlikleri & Parametreler \\
\hline Yalancı birinci derece & $\log \left(q_{e}-q_{t}\right)=\log \left(q_{e}\right)-\frac{k_{1}}{2.303} t$ & $\begin{array}{ll}q_{e} & \text { dengedeki metal iyonu konsantrasyonu }\left(\mathrm{mg} \mathrm{g}^{-1}\right) \\
q_{t} & \mathrm{t} \text { anında adsorplanan adsorbat derişimi }\left(\mathrm{mg} \mathrm{g}^{-1}\right) \\
k_{l} & \text { yalancı birinci dereceden hız sabiti }\left(\mathrm{dk}^{-1}\right)\end{array}$ \\
\hline Yalanct ikinci derece & {$\left[\frac{t}{q_{t}}\right]=\frac{1}{k q_{e}}+\frac{1}{q_{e}} t$} & $\begin{array}{ll}q_{t} & \mathrm{t} \text { anında adsorplanan adsorbat derisimi }\left(\mathrm{mg} \mathrm{g}^{-1}\right) \\
k_{2} & \text { yalancı ikinci dereceden hız sabiti }\left(\mathrm{dk}^{-1}\right)\end{array}$ \\
\hline Elovich & $q_{t}=\frac{1}{\beta} \operatorname{In}(\alpha \beta)+\frac{1}{\beta} \operatorname{In}(t)$ & $\begin{array}{ll}\alpha & \text { başlangıç adsorpsiyon hız sabiti }\left(\mathrm{mg} \mathrm{dk}^{-1}\right) \\
\beta & \text { desorpsiyon sabiti }\left(\mathrm{g} \mathrm{mg}^{-1}\right)\end{array}$ \\
\hline Bangham & $\begin{aligned} \log \log \left(\frac{C_{o}}{C_{o}-q_{t} m}\right)= & \log \left(\frac{k_{o} m}{2.303 V}\right) \\
& +\alpha \log t\end{aligned}$ & $\begin{array}{ll}C_{o} & \text { Çözeltideki adsorbatın başlangıç konsantrasyonu }\left(\mathrm{mg} \mathrm{L}^{-1}\right) \\
V & \text { Çözelti hacmi } \\
q_{t} & \mathrm{t} \text { anında adsorplanan adsorbat derişimidir }\left(\mathrm{mg} \mathrm{g}^{-1}\right)\end{array}$ \\
\hline
\end{tabular}

Tablo 6. $\mathrm{Cu}(\mathrm{II})$ ve $\mathrm{Zn}$ (II) iyonlarının biyosorpsiyonunun kinetik parametreleri

\begin{tabular}{|c|c|c|c|c|c|}
\hline \multicolumn{2}{|c|}{ Kinetik modelleri } & \multicolumn{2}{|c|}{$\mathrm{Cu}$ (II) } & \multicolumn{2}{|c|}{ Zn (II) } \\
\hline & & YK & PK & YK & PK \\
\hline \multirow{4}{*}{$\begin{array}{l}\text { Yalanct } \\
\text { derece }\end{array}$} & $q_{e}\left(m g g^{-1}\right)$ & 4.1700 & 4.2500 & 4.1700 & 4.2500 \\
\hline & $k_{l}\left(L \boldsymbol{m g}^{-1}\right)$ & 5.3760 & 7.9360 & 5.3760 & 7.9360 \\
\hline & $R^{2}$ & 0.8251 & 0.7054 & 0.8251 & 0.7054 \\
\hline & $q_{e}\left(m g g^{-1}\right)$ & 2.8000 & 2.3100 & 3.6400 & 4.1000 \\
\hline \multirow[t]{2}{*}{ Yalancı ikinci derece } & $k_{2}\left(g m g^{-1} \cdot d k^{-1}\right)$ & 0.0200 & 5.2890 & 0.0100 & 0.0060 \\
\hline & $R^{2}$ & 0.8428 & 0.8649 & 0.8404 & 0.8447 \\
\hline \multirow{4}{*}{ Elovich } & $\beta\left(g m g^{-1}\right)$ & 1.9400 & 2.2400 & 1.9400 & 1.7000 \\
\hline & $\alpha\left(m g g^{-1} \cdot d k^{-1}\right)$ & 0.1800 & 1.2000 & 0.1200 & 0.1000 \\
\hline & $\boldsymbol{R}^{2}$ & 0.8125 & 0.8816 & 0.8536 & 0.8359 \\
\hline & $\alpha\left(m g g^{-1} \cdot d k^{-1}\right)$ & 0.4345 & 0.6101 & 0.8100 & 0.8094 \\
\hline \multirow[t]{2}{*}{ Bangham } & $k\left(m L\left(g L^{-1}\right)\right)$ & 0.0040 & 0.0010 & 0.0009 & 0.0008 \\
\hline & $R^{2}$ & 0.8407 & 0.8017 & 0.8255 & 0.8255 \\
\hline
\end{tabular}

\section{Sonuçlar}

$\mathrm{Bu}$ çalışmada, atıksulardan bakır ve çinko metal iyonlarının gideriminde fistık kabuğu ve pirinç kabuğu biyokütlelerinin kullanımı araştırılmıştır. Biyokütlelerin karakterizasyonu, SEM-EDS, FTIR analizleri ile gerçekleştirilmiştir. YK ve PK'nun, bakır ve çinko biyosorpsiyonu öncesi ve sonrası SEM-EDS görüntüleri incelenmiştir. FTIR spektrumları incelendiğinde, YK ve PK; $995 \mathrm{~cm}^{-1}$ 'deki karakteristik pik, $\mathrm{C}=\mathrm{C}$ gerilme titreşimine aittir. Biyosorpsiyon çalışmaları, $\mathrm{pH} ; 3-11$ aralığında, $25^{\circ} \mathrm{C}$ sıcaklıkta, $25 \mathrm{mg} \mathrm{L}^{-1}$ başlangıç metal konsantrasyonunda ve $180 \mathrm{dk}$ sürede gerçekleştirilmiştir. pH'ın artarken, $\mathrm{Cu}$ (II) ve Zn(II)'un sorpsiyon kapasitesinin arttığı görülmektedir. 
Biyosorpsiyon çalışmaları, Langmuir, Freundlich ve Temkin izotermlerine göre değerlendirilmiştir. İzoterm modelleri, korelasyon katsayılarına $\left(\mathrm{R}^{2}\right)$ göre karşılaştırıldığında, uygulanan izoterm modellere uygunluk göstermektedir. Biyosorpsiyon çalışmaları, hem heterojen hem de homojen yüzeylerde gerçekleşmektedir ve adsorbat molekülleri ile biyosorbentler arasında etkileşim olmaktadır.

Kinetik çalışmaları, yalancı birinci dereceden, yalancı ikinci dereceden, Elovich ve Bangham modellerine göre değerlendirilmiştir. Kinetik modellere ait regresyon katsayıları $\left(\mathrm{R}^{2}\right)$ incelendiğinde, en yüksek değerlerin yalancı ikinci derece kinetik modelinden elde edildiği görülmektedir. Atıksulardaki $\mathrm{Cu}(\mathrm{II})$ ve $\mathrm{Zn}$ (II) iyonlarının gideriminde en uygun kinetik model; yalancı ikinci derece kinetik modeldir.

\section{Çıkar çatışması}

Yazarlar çıkar çatışması olmadığını beyan etmektedir.

Benzerlik oranı (iThenticate): $\% 20$

\section{Kaynaklar}

[1] Ş. Kaypak, Bilim ve teknolojinin gelişiminin çevreye yansıması. Uluslararas1 Sosyal Bilimler Kongresi, Adana, Türkiye, 8-10 Mart 2019.

[2] Z. Öztemel, Ş. Tüfenkçi ve T. Çakmakcı, motorlu taşıtlardan kaynaklanan ağırmetal kirliliğinin belirlenmesi: Şanlıurfa-Viranşehir karayolu örneği, YYÜ Tar. Bil. Derg., 26(2), 282-287, 2016.

[3] M. Ş. Dündar, H. Altundağ, S. Kaygaldurak, V. Şar ve A. Acar, Çeşitli endüstriyel atık sularda ağır metal düzeylerinin belirlenmesi. SAÜ Fen Bilimleri Dergisi, 16(1), 6-12, 2012.

[4] A. Esmaeilli, and N. Khoshnevisan, Optimization of process parameters for removal of heavy metals by biomass of $\mathrm{Cu}$ and $\mathrm{Co}$-doped alginate-coated chitosan nanoparticles. Bioresource technology, 218, 650-658. 2016. https://doi:10.1016/j.biortech.2016.07.005

[5] F. Fu, and Q. Wang, Removal of heavy metal ions from wastewaters: A rewiev. J. Environmental Management, 92(3), 407-414, 2011. https://doi:10.1016/ j.jenvman.2010.11.011.

[6] M. Fomina, and G. M. Gadd, Biosorption: current perspectives on concept, definition and alication, Bioresource Technology, 160, 3-14, 2014. https://doi:10.1016/j.biortech.2013.12.102.

[7] M. Edelstein, and M. Ben-Hur, Heavy metals and metalloids: Sources, risks and strategies to reduce their accumulation in horticultural crops. Sci. Hortic. 234, 431-444, 2018. https://doi:10.1016/j.scienta. 2017.12.039.

[8] K. H. Vardhan, P. S. Kumar, and R. C. Panda, A rewiev on heavy metal pollution, toxicity and remedial measures: Curret trends and future perspectives. Journal of Molecular Liquids, 290, 111-197, 2019. https://doi: 10.1016/j.molliq.2019.111197.

[9] M. Xu, P. Hadi, G. Chen, and G. Mckay, Removal of cadmium ions from wastewater using innovative electronic waste-derived material. J. Hazard. Mater.
273, 118-123, 2014. https://doi:10.1016/j.molliq. 202019.111197

[10] A. Maleki, B. Hayati, F. Najafi, F. Gharibi, and S. W. Joo, Heavy metal adsorption from industrial wastewater by $\mathrm{PAMAM} / \mathrm{TiO}_{2}$ nanohybrid: Preparation, characterization and adsorption studies. J. Mol. Liq. 224, 95-104, 2016. https://doi:10.1016/ j.molliq.202016.09.060.

[11] A. Kolbasov, S. Sinha-Ray, A. I. Yarin, and B. Pourdeyhimi, Heavy metal adsortion on solution-blown biopolymer nanofiber membranes. J. Membr. Sci. 530, 250-263, 2017. j.memsci.2017.02.019.

[12] J. Singh, M. Sharma, and S. Basu, Heavy metal ions adsorption and photodegradation of remazol black XP by iron oxide/silica monoliths: Kinetic and equilibrium modelling. Adv. Powder Technol., 29(9), 2268-2279, 2018. https://doi:10.1016/j.apt.2018.06.011.

[13] V. Manirethan, K. Raval, R. Rajan, H. Tharia, and R. M. Balakrishnan, Kinetic and thermodynamic studies on the adsorption of heavy metals from aqueous solution by melanin nanopigment obtained from marine source: Pseudomonas stutzeri. J. Environmental Management, 214, 315-324, 2018. https://doi: 10.1016/j.jenvman.2018.02.084.

[14] A. Rether, Entwicklungund charakterisierung wasserlöslicher benzoylthioharnst offfunktio nalisierter polymere zur selektiven abtrennung von schwermetallionen aus abwassern und prozesslösungen, Dokrora Tezi, Münih Teknik Üniversitesi, München, Almanya, 2002.

[15] G. Özbolat and A. Tuli, Effects of heavy metal toxicity on human health, Archives Medical Review Journal, 25(4), 502-521, 2016.

[16] A. Şama, Taşköprü (Kastamonu) Atıksu Arıtma Tesisi İçin Proje Aşamasında öngörülen ve mevcut durumda sağlanan verimin sürekliliğinin karşılaştırılması. Journal Of Personality And Social Psychology, 1(1), 118-1197, 2017.

[17] F. Zhao, W. Yang, Z. Zeng, H. Li, X. Yang, Z. He, B. $\mathrm{Gu}$, M. T. Rafig, and H. Peng, Nutrient removal efficiency and biomass production of different bioenergy plants in hypereutrophic water. Biomass Bioenergy, 42, .212-218, 2012. https://doi: 10.1016/j.biombioe.2012.04.003.

[18] Y. Yao, B. Gao, J. Chen, and I. Yang, Engineered biochar reclaiming phosphate from aqueous solutions: mechanisms and potential alication as a slow-release fertilizer. Environ. Sci. Technol. 47(15), .8700-8708, 2013. https://doi:10.1021/es4012977.

[19] E. H. Gürkan, and S. Çoruh, Equilibrium and kinetic adsorption study of aqueous basic dye solutions using waste foundry sand. International Journal of Global Warming, 11(1), .87-106, 2018. https://doi:10.1504 /IJGW.2017.080991.

[20] S. Bayar, R. Boncukcuoglu, B. A. Fil ve A. E. Y1lmaz, Elektrokoagülasyon yöntemi kullanılarak Direct Red 23 boyar maddesinin gideriminin incelenmesi. Iğdır Üni. Fen Bilimleri Enst. Der., 2(2), .21-28, 2012. 
[21] A. K. Verma, R. R. Dash, and P. Bhunia, A review on chemical coagulation/flocculation technologies for removal of colour from textile wastewaters. Journal of Environmental Management, 93, 154-168, 2012. https://doi:10.1016/j.jenvman.2011.09.012.

[22] B. Lam, S. Deon, N. Morin-Crini, G. Crini, and P. Fievet, Polymer-enhanced ultrafiltration for heavy metal removal: Influence of chitosan and carboxymethyl cecculose on filtration performances. J. Clean Prod., 171, 927-933, 2018. https://doi: 10.1016/j.jclepro.2017.10.090.

[23] P. R. Choudhury, S. Majumdar, G. C. Sahoo, S. Saha, and P. Mondal, High pressure ultrafiltration $\mathrm{CuO} /$ hydroxyethyl cellulose composite ceramic membrane for seperation of $\mathrm{Cr}(\mathrm{VI})$ and $\mathrm{Pb}(\mathrm{II})$ from contaminated water. Chem. Eng.. J,. 336, .570-578, 2018. https://doi:10.1016/j.cej.2017.12.062.

[24] V. J. Inglezakis, M. M. Fyrillas, and M. A. Stylianou, Two-phase homogeneous diffusion model for the fixed bed sorption of heavy metals on natural zeolites. Microporous Mesoporous Mater. 266, 164-176, 2018. https://doi:10.1016/j.micromeso.2018.02.045.

[25] S. S. Obaid, D. K. Gaikwad, M. I. Sayyed, K. ALRashdi, and P. P. Pawar, Heavy metal ions removal from waste water by the natural zeolites. Mater. Today Proc. 5(9), 17930-17934, 2018. https://doi:10.1016 /j.matpr.2018.06.122.

[26] R. Gayathri, K. P. Gopinath, P. S. Kumar, and S. Suganya, Adsorption capabilityof surface modified jujube seeds for $\mathrm{Cd}(\mathrm{II}), \mathrm{Cu}(\mathrm{II})$ and $\mathrm{Ni}(\mathrm{II})$ ions removal:mechanism, equilibrium, kinetic and thermodynamic analysis. Desalination Water Treat., 140, 268-282, 2019. https://doi:10.5004/dwt. 2019.23405 .

[27] G. Z. Kyzas, G. Bomis, R. L. Kosheleva, E. K. Efthimiadou, E. P. Favvas, M. Kostoglou, and A. C. Mitropoulos, Nanobubbles effect on heavy metal ions adsorption by activated carbon. Chem. Eng. J., 356, 9197, 2019. https://doi:10.1016/j.cej.2018.09.019.

[28] S. D. Gisi, G. Lofrano, M. Grassi, and M. Notarnicola, Characteristics and adsorption capacities of low-cost sorbents for wastewater treatment: A review. Sustainable Materials and Technologies. 9, 10-40, 2016. https://doi:10.1016/j.susmat.2016.06.002

[29] M. Sharma, J. Singh, S. Hazra, and S. Basu, Adsorption of heavy metal ions by mesoporous $\mathrm{ZnO}$ and $\mathrm{TiO}_{2} / \mathrm{ZnO}$ monoliths: Adsorption and kinetic studies. Microchem. J. 145, 105-112, 2019. https://doi:10.1016/j.microc. 2018.10.026.

[30] S. Sun, J. Zhu, Z. Zheng, J. Li, and M. Gan, Biosynthesis of $\beta$-cyclodextrin modified SchWertmannite and the alication in heavy metals adsorption. Powder Technol., 342, 181-192, 2019. https://doi:10.1016/j.powtec.2018.09.072.

[31] P. R. Yaashikaa, P. S. Kumar, V. P. M. Babu, R. K. Durga, V. Manivasagan, K. Saranya, and A. Saravanan, Modelling on the removal of $\mathrm{Cr}(\mathrm{VI})$ ions from aquatic system using mixed biosorbent. J. Mol. Liq., 276, 362 370, 2019. https://doi:10.1016/j.molliq.2018.12.004.
[32] L. H. Velazquez-Jimenez, A. Pavlick, J. R. RangelMendez, Chemical characterization of raw and treated agave bagasse and its potential as adsorbent of metal cations from water. Ind. Crop. Prod. 43, 200-206, 2013. https://doi:10.1016/j.indcrop.2012.06.049

[33] W. Zou, I. Zhao, and I. Zhu, Efficient uranium (VI) biosorption on grapefruit peel: Kinetic study and thermodynamic parameters. J. Radioanal. Nuci. Chem., 292, 1303-1315, 2012. https://doi:10.1007/s10967011-1602-0.

[34] T. Aman, A. A. Kazi, M. U. Sabri, and Q. Bano, Potato peels as solid waste fort he removal of heavy metal coer(II) from waste water/industrial effluent. Colloids Surf. B: Biointerfaces, 63, 116-121, 2008. https://doi:10.1016/j.colsurfb.2007.11.013.

[35] E. Malkoc and Y. Nuhoglu, Investigations of Nickel(II) removal from aqueous solutions using tea factory waste. Journal of Hazardous Material, 127(1), 120-128, 2005. https://doi:10.1016/j.jhazmat.2005.06.030.

[36] K. Kadirvelu, K, Thamaraiselvi and C.Namasivayam, Adsorption of Nickel(II) from aqueous solution onto activated carbon prepared from coirpith. Separation and Purification Technology, 24(3), 497-505, 2001. https://doi:10.1016/S1383-5866(01)00149-6.

[37] H. N. Köysüren, and Ş. Dursun, The removal of heavy metal 1ons from the aquatic environment by modified apricot kernel shell. Journal of the Faculty of Engineering and Architecture of Gazi University, 28(2), 427-435, 2013.

[38] O. Gök, and Ö. Çimen Mesutoğlu, Olive pomace as a low-cost adsorbent for the removal heavy metals. Journal of the Faculty of Engineering and Architecture of Gazi University, 32(2), 507-516, 2017.

[39] A. Bhatnagar, and M. Sillanpaa, Utilization of agroindustrial and municipal waste materials as potential adsorbents for water treatment: A review. Chem. Eng. J., 157(2-3), 277-296, 2010. https://doi:10.1016/ j.cej.2010.01.007.

[40] A. Bhatnagar, M. Sillanpaa, and A. Witek-Krowiak, Agricultural waste peels as versatile biomass for water purification: A review. Chem. Eng. J., 270, 244-271, 2015. https://doi:10.1016/j.cej.2015.01.135.

[41] J. J. Liu, X. C. Wang, and B. Fan, Characteristics of PAHs adsorption on inorganic particles and activated sludge in domestic wastewater treatment. Bioresource Technol., 102(9), 5305-5311, 2011. https://doi: 10.1016/j.biortech.2010.12.063.

[42] A. Gupta, and A. Garg, Utilisation of sewage sludge derived adsorbents for removal of recalcitrant compounds from wastewater: mechanistic aspects, isoterms, kinetics and thermodynamics. Bioresource Technol., 194, 214-224, 2015. https://doi:10.1016 /j.biortech.2015.07.005.

[43] R. Malik, D. S. Ramteke, and S. R. Wate, Adsorption of malachite gren on groundnut shell waste based powdered activated carbon, Waste Management, 27, 1129-1138, 2007. https://doi:10.1016/j.wasman. 2006.06.009. 
[44] E. Pehlivan, T. Altun, and S. Parlayıcı, Modified barley straw as a potential biosorbent for removal of coer ions from aqueous solution. Food Chem., 135, 2229-2234, 2012. https://doi:10.1016/j.foodchem.2012.07.017.

[45] P. Tasaso, Adsorption of coer using pomelo peel and depectinated pomelo peel, Journal of Clean Energy Technology, 2(2), 154-157, 2014. https://doi:10.7763 /jocet.2014.v2.112.

[46] W. P. Putra, A. Kamari, S. N. M. Yusoff, C. F. Ishak, A. Mohammed, N. Hashim, and I. Md. Isa, Biosorption of $\mathrm{Cu}$ (II), $\mathrm{Pb}$ (II) and $\mathrm{Zn}$ (II) Ions from aqueous solutions using selected waste materials: Adsorption and characterisation studies. Journal of Encapsulation and Adsorption Sciences, 4, .25-35, 2014. https://doi: 10.4236/jeas.2014.41004.

[47] H. Arslanoglu, H. S. Altundogan, and F. Tumen, Heavy metals binding properties of esterified lemon. Journal of Hazardous Materials, 164, 1406-1413, 2009. https://doi:10.1016/j.jhazmat.2008.09.054.

[48] Q. Qian, K. Mochidzuki, T. Fujii, and A. Sakoda, Removal of coer from aqueous solution using ironcontaining adsorbents derived from methane fermentation sludge. Journal of Hazardous Materials, 172, 1137-1144, 2009. https://doi:10.1016/j.jhazmat. 2009.07.107.

[49] M. Topal, E. I. Arslan Topal ve S. Aslan, Limon kabuğu kullanarak sulu çözeltilerden $\mathrm{Cu}$ (II) giderimi, Erciyes Üniversitesi Fen Bilimleri Enstitüsü Dergisi, 27(3), 265-270, 2011.7
[50] M. H. Morcali, B. Zeytuncu, and O. Yucel, Platinum uptake from chloride solutions using biosorbents, Materials Research, 16(2), 528-538, 2013, https://doi:10.1590/S1516-14392013005000006.

[51] S. Boumchita, Y. Benjelloun, and S. Lairini, Alication of peanut shell as a low-cost adsorbent for the removal of anionic dye from aqueous solutions. Journal of Materials and Environmental Science, 8(7), 23532364, 2017.

[52] B. Zhou, Z. Wang, D. Shen, F. Shen, C. Wu and R. Xiao, Low cost earthworm manure-derived carbon material for the adsorption of $\mathrm{Cu} 2+$ from aqueous solution: Impact of pyrolysis temperature. Ecol. Eng., 98, 189-195, 2017. https://doi:10.1016/j.ecoleng. 2016.10.061.

[53] C. Yu, M. Wang, X. Dong, Z. Shi, X. Zhang and Q. Lin, Removal of $\mathrm{Cu}$ (II) from aqueous solution using $\mathrm{Fe}_{3} \mathrm{O}_{4}$-alginate modified biochar microspheres. RSC Adv., 7, 53135-53144, 2017. https://doi:10.1039/ c7ra10185f.

[54] M. Okur ve D. D. Eslek Koyuncu, Atık yumurta kabuklarından sentezlenen hidroksiapatitin Remazol N.Blue RGB boyarmaddesinin adsorpsiyonunda değerlendirilmesi. Journal of the Faculty of Engineering and Architecture of Gazi University, 35(1), 419-430, 2020. https://doi:10.17341/gazimmfd.474350. 